\title{
O mau cheiro como estratégia de sobrevivência*1
}

\author{
Tomás Moraes Abreu Bonomi*2 \\ Manoel Tosta Berlinck*3
}

$O$ presente trabalho tem como base a narrativa de um atendimento clínico, no qual a paciente procura análise, pois todos os seus relacionamentos amorosos fracassavam causando-lhe intenso sofrimento. Ao longo dos atendimentos ela diz saber o porquê desses fracassos: ela fede. Formulamos a hipótese clínica de que o mau cheiro se insere na economia psíquica da paciente como um mecanismo de defesa e, tomando o conceito de narcisismo como norteador, discutimos o papel da alucinação olfativa na sustentação psíquica da paciente.

Palavras-chave: Alucinação olfativa, narcisismo, mecanismo de defesa, psicanálise

${ }^{* 1} \mathrm{O}$ artigo baseia-se na dissertação de Mestrado intitulada $O$ mau cheiro: Sobre as bases da sustentação psíquica. Bonomi, T. M. A (2015). Programa de Psicologia Clínica, Pontifícia Universidade Católica de São Paulo - PUC-SP, São Paulo, orientado pelo Prof. Dr. Manoel Tosta Berlink.

*2 Mestre no Programa de Estudos Pós-Graduados em Psicologia Clínica da Pontifícia Universidade Católica de São Paulo - PUC-SP (São Paulo, SP, Br).

${ }^{* 3}$ Pontifícia Universidade Católica de São Paulo - PUC-SP (São Paulo, SP, Br). 


\section{ARTIGOS}

\section{Introdução}

"Minha dificuldade em arranjar uma namorada acontece por causa do meu cheiro" (sic). Sandra produz essa fala no início de sua análise. De fato, a temática do mau cheiro circundou de diversas formas todo o seu processo analítico que teve duração de dois anos.

Sandra é homossexual, terceira filha de uma família de quatro irmãs, na casa dos 35 anos, solteira, mora sozinha e trabalha como diarista. A demanda inicial situava-se na impossibilidade de encontrar um amor e na certeza de que teria algo de errado com ela.

Por um lado Sandra apresentava grandes dificuldades afetivas: evitava os contatos sociais e procurava o isolamento, sentia-se incompreendida pela família, tinha nojo dos homens e, em momentos de crise, sentia exalar um fedor e pensava em se suicidar. Por outro, era detentora de um rico senso de humor, gostava muito de seu trabalho com o qual se sustentava financeiramente, possuía alguns amigos e atividades de lazer, gostava de flertar com mulheres nas ruas e teve a iniciativa de procurar uma análise.

O mau cheiro aparece inicialmente como uma preocupação objetiva da paciente em relação a um excesso de suor, preocupação esta que se insere diretamente na transferência quando convoca o analista a dizer se sentia ou não o seu cheiro. Após alguns meses, o mau cheiro ressurge em seu discurso através de uma memória traumática de sua adolescência - uma cena em que sua namorada afirma que não ficaria com ela por causa de seu cheiro -; tal memória serve como substrato para confirmar a ideia de que o seu odor provocaria o fracasso de seus relacionamentos. Passaram-se alguns meses sem que o mau cheiro surgisse no discurso da paciente, até que brota explicitamente em um sonho. Nesse, a paciente dá a luz a um bebê envolto em um líquido mau cheiroso, o que a angustia e acaba por despertá-la. Por fim, o mau cheiro aparece em um momento de crise quando, ao atravessar um rompimento amoroso, Sandra vive uma situação de intensa 
desestruturação psíquica e alucina o mau cheiro, signo de um pathos que a invade.

O enigma tratado neste caso foi justamente compreender como uma pessoa com tamanhas angústias e mecanismos de defesa arcaicos conseguia se sustentar subjetivamente e construir uma vida mais ou menos adaptada e satisfatória. Logo, neste artigo, buscaremos desvendar alguns dos possíveis papéis e funções do fenômeno do mau cheiro na economia psíquica da paciente.

\section{$O$ cheiro e o olfato em Freud}

Ao longo da obra de Freud, o olfato aparece algumas vezes associado à sexualidade infantil, ao fetiche (cropofilia), a desordens sensoriais na histeria e aos estágios ontológicos da evolução do homem.

Ainda no período das publicações pré-psicanalíticas, Freud escreve uma carta a Fliess (carta 55), datada de 11 de janeiro de 1897, em que faz referência ao olfato, principalmente quanto à relação da psicose com os abusos sexuais na infância. Freud estabelece uma relação entre o olfato e a sexualidade: o cheiro portaria em si um componente parcial da libido; porém, com o decorrer do desenvolvimento da sexualidade infantil, daria lugar a uma sexualidade centrada nas zonas erógenas genitais. Dessa forma, compreendemos que para Freud, ainda no início do desenvolvimento de sua obra, na histeria ocorreria um retrocesso libidinal, uma vez que as funções olfativas, tanto aumentadas quanto anestesiadas, voltariam a ocupar um lugar de destaque na sexualidade.

Uma outra compreensão decorrente dessa carta refere-se à ideia do olfato como parte integrante do instinto sexual no homem primitivo, função esta que foi sendo perdida conforme o desenvolvimento da espécie e da civilização. Quanto a isso, Freud (1930/1996g), em nota de rodapé em "Mal-estar na civilização", declara:

A periodicidade orgânica do processo sexual persistiu, é verdade, mas seu efeito sobre a excitação sexual psíquica foi invertido. Parece mais provável, que essa modificação se tenha vinculado à diminuição dos estímulos olfativos, através dos quais o processo menstrual produzia efeitos sobre a psique masculina. (p. 105)

Freud constrói uma espécie de genealogia da raça humana, que teria como momento-chave a adoção da postura ereta. Uma decorrência direta 


\section{ARTIGOS}

dessa nova postura refere-se à desvalorização do olfato enquanto sentido sexual, devido ao isolamento do contato direto do nariz com os odores do período menstrual.

Esse processo evolutivo marcaria o início da regulação da atividade sexual que, segundo Freud, seria um acontecimento ontológico central para o surgimento da ideia de família como unidade de filiação parental e, por consequência, para o estabelecimento das bases da civilização.

Outro fator que estaria no cerne da criação do processo civilizatório decorre da transformação da finalidade sexual: de meramente reprodutiva para a exclusiva obtenção de um prazer. Mudança esta que, segundo Freud (1930/1996g), seria um dos marcos na diferenciação entre os homens e os animais.

Além disso, o autor afirma que, concomitantemente ao movimento da expropriação do olfato, ocorre o surgimento da ideia de limpeza, pois os maus cheiros provenientes dos excrementos, que anteriormente estavam ligados aos impulsos sexuais, passam a ser recriminados e punidos. Assim, são associados à vergonha e, como consequência dessa associação, a limpeza passa a habitar a cultura como um dos principais valores em qualquer forma de educação.

Contudo, na mesma nota de rodapé, Freud faz uma ressalva: apesar da moral civilizatória da limpeza, os excrementos permanecem valiosos para as crianças pequenas, sobretudo na ideia de que são partes destacáveis de seus próprios corpos.

Uma segunda carta de Freud a Fliess (carta 75), também de 1897, registra a tentativa de Freud em conceber o mecanismo do recalque. Nela, o autor faz referência à ideia do abandono da sexualidade mediante o implemento da postura ereta nos humanos como elemento fundante do recalque, uma vez que uma série de sensações, como o cheiro, que outrora proporcionavam excitações sexuais, transformaram-se e passaram a despertar repulsa. Ou seja, o momento em que uma fonte de prazer interno se transforma em fonte de repugnância interna seria, para Freud, uma espécie de proto-recalque ontológico, que funcionaria como modelo de apresentação do recalque.

Interessante notar que o mau cheiro, neste momento da obra de Freud, aparece intrinsecamente ligado a uma sexualidade perdida-recalcada, de forma que, mesmo perdendo seu estatuto de primazia no ato sexual, permaneceria para sempre como resto mnêmico. 


\section{A clínica e o olfato}

O principal caso clínico encontrado na obra freudiana que possui o cheiro e o olfato como elementos centrais é o de Miss Lucy, descrito no livro "Estudos sobre a histeria" (1893-1895/1996a)). Essa paciente procurou ajuda, pois havia perdido os sentidos do olfato, com exceção de algumas sensações olfativas que the causavam grande aflição. Freud toma esses odores como manifestações alucinadas que estariam ligadas a traumas: “(...) deveria ser possível encontrar uma experiência em que esses odores, que agora haviam se tornado subjetivos, tivessem sido objetivos. Essa experiência devia ter sido o trauma que as sensações recorrentes do olfato simbolizavam na memória" (p. 134).

Para Freud, seria imprescindível encontrar algum objeto concreto que se conectasse com a sensação subjetiva olfativa. No caso de Miss Lucy, era um cheiro de pudim queimado. A paciente era governanta em uma casa habitada por duas crianças e o pai delas; a mulher (mãe das crianças) falecera. Havia uma característica particular dessa governanta: conhecera toda a família antes da perda materna e, no leito de morte da mãe, prometera cuidar de seus filhos.

Em determinado momento da análise, a paciente acabou revelando uma memória: as crianças roubaram uma carta que Lucy havia recebido da mãe dela quando, exatamente nesse instante, sentiu o cheiro de um pudim real queimando.

Por associações, chegou-se ao conflito: a paciente nutria sentimentos amorosos pelo pai das crianças, mas como percebera que tal vontade não iria se realizar, resolvera deixar a casa. A carta recebida representava uma conversa com sua mãe sobre o desejo de partir; no entanto, tal desejo se opunha à promessa feita à mãe das crianças.

Essa cadeia de associação psíquica provocou o desaparecimento do cheiro de pudim queimado. Apesar disso, pouco tempo depois surgiu um cheiro de fumaça de cachimbo também persistente e causador de grande angústia.

Com o seguimento da análise, o cheiro de fumaça de cachimbo foi associado a uma briga entre seu patrão e um amigo, enquanto fumavam cachimbos, ocorrida por conta deste senhor (amigo do patrão) ter beijado as crianças como um gesto de ternura, ato que irritou tremendamente o pai. Em seguida, Miss Lucy associou esta cena a uma segunda, em que o patrão the impunha uma severa reprimenda, pois em determinado dia um convidado havia beijado suas filhas e, nesse momento, o pai lhe disse que se isso voltasse a acontecer ela seria demitida. Esse evento simbolizou para Miss Lucy a perda 


\section{ARTIGOS}

de qualquer esperança de um dia realizar seu amor pelo patrão, assim como continha em si o trauma original associado ao cheiro da fumaça de cachimbo. Após essa revelação, Miss Lucy não só parou de sentir o cheiro do cachimbo, como passou a se sentir mais feliz e fortalecida psiquicamente.

Um cheiro como expressão de um sintoma histérico, às vezes associado a alergias, também aparece em casos clínicos descritos por McDougall (1997) e Abud (2006). Em todos esses casos, uma ideia incompatível com o ego é recalcada; no entanto, o afeto presente em tal situação permanece na consciência, na forma de uma reminiscência olfativa surgida por um processo conversivo. $\mathrm{O}$ trabalho analítico, pela associação livre, permite refazer o percurso de deslocamento psíquico do cheiro à situação traumática inconsciente. Tal associação psíquica levaria à eliminação da angústia, tal qual o modelo da ab-reação.

Diferentemente dessa lógica sintomatológica, o cheiro, no caso de Sandra, não parece apresentar a função principal de comprimir em si uma representação deslocada de um evento ou de uma fantasia traumática. O cheiro possui, sim, um conteúdo enigmático, mas se apresenta em um contexto diferente, pois surge somente em situações de crise, quando a paciente não possui mais capacidade de representação. Uma segunda diferença corresponde à fonte do odor que, no caso de Sandra, seria ela mesma.

De forma semelhante, encontramos um caso clínico discutido por Alonso (2012), em que o cheiro, pelas associações, não se apresenta como uma representação deslocada de um evento traumático, mas sim como um mecanismo de defesa (alucinação) que barra a emergência de pulsões ainda mais destrutivas. Aqui, a paciente voltava de um período de duas semanas sem ter sessões e ao retornar, percebe que a analista está grávida, e passa a sentir um "cheiro de merda" no consultório. A posteriori, a analista relaciona a visão de sua barriga com uma dinâmica psíquica traumática de ausência, pois a paciente era gêmea e tinha nascido em segundo lugar, em uma época em que não havia grande tecnologia de ultrassonografia; ou seja, sua mãe esperava somente uma criança.

A visão da barriga ativou um trauma impossível de ser representado; logo, o cheiro alucinado funcionou como defesa do contato com um estado de desamparo presente na dinâmica traumática de ausência. Conforme Alonso "Isso não nega que há uma verdade histórica, como em toda alucinação, mas toda ela está condensada numa marca sensorial: o cheiro. Marca que sutura o tempo num presente absoluto" (p. 192).

Em outras palavras, a alucinação não está representando algo: ela surge justamente porque não havia capacidade de representar. Dessa forma, 
a presença de fenômenos olfativos na clínica psicanalítica podem tanto se apresentar como mecanismo de defesa conversivo, ao condensar em si uma situação traumática associada ao cheiro, como podem adquirir o valor de uma defesa alucinatória primitiva, que protegeria o psiquismo de uma desintegração egoica.

Logo, tomamos como ponto de partida a compreensão do mau cheiro como expressão de um sintoma que protegeria a paciente de conteúdos e afetos aterrorizantes que geralmente eclodem nos momentos de desilusão amorosa.

\section{Narcisismos}

Nessa linha de raciocínio, a eclosão do mau cheiro nos momentos de grande angústia e desorganização egoica pode ser concebida como uma tentativa desesperada de seu psiquismo para encontrar contorno e continente identitário. A concepção de que o mau cheiro trabalharia a favor da unificação egoica da paciente nos remete ao conceito do narcisismo e às vicissitudes dos investimentos de objeto.

O termo narcisismo aparece, pela primeira vez, em 1905, em "Três ensaios sobre a sexualidade", para descrever o tipo de escolha objetal nos homossexuais. No entanto, foi somente em 1914 com "Sobre o narcisismo: uma introdução", que o termo ganhou o estatuto de conceito na obra freudiana.

De acordo com Roudinesco (1998), Freud se apoia na descrição da psicose feita por Karl Abraham, como um estado psíquico em que a libido seria retirada dos objetos externos e reinvestida no próprio ego, para descrever e elaborar a dinâmica pulsional no narcisismo: "A libido afastada do mundo externo é dirigida para o ego e assim dá margem a uma atitude que pode ser denominada de narcisismo" (Freud, 1996e/1914, p. 82).

Em um primeiro momento, Freud localiza o narcisismo na dinâmica pulsional presente nos estados maníacos, depois amplia o escopo do conceito para descrever o momento - do desenvolvimento infantil - em que a criança investe toda sua libido em si mesma.

A afirmação sobre o narcisismo ser um estágio da formação do aparelho psíquico produz no autor uma pergunta importante: Qual seria a relação entre o narcisismo e um estado inicial de libido denominado autoerotismo? Freud afirma que, no início da vida mental do bebê, não haveria uma 


\section{ARTIGOS}

formação análoga ao ego; logo, esse momento do desenvolvimento es- taria regido pelas forças das pulsões parciais que buscam satisfações exclusivamente em seu próprio corpo. Dessa forma, haveria de existir uma ação psíquica que, adicionada aos instintos autoeróticos, promovesse a unidade egoica; o narcisismo.

Nessas bases, o narcisismo despontaria quase concomitantemente à formação do ego e, após sua constituição, surgiriam os primeiros objetos de amor do bebê: ele próprio e a pessoa que dele cuida e o alimenta, geralmente a mãe. A esse momento inicial do desenvolvimento do ego, em que todo investimento libidinal do bebê se direciona a ele próprio, Freud denomina de narcisismo primário.

O narcisismo secundário, por sua vez, aconteceria em um momento posterior à constituição plena do ego. Nesse período de desenvolvimento do psiquismo, as pulsões libidinais se dirigem a objetos externos e depois retornam ao ego, sendo que o retorno da libido, marcado pelas identificações com objetos externos, produz transformações no ego. Esse movimento dialético dos investimentos de ego e de objeto corresponde ao narcisismo secundário.

Françoise Dolto (1992) propõe o conceito de narcisismo primordial, referente à influência dos desejos, sonhos e expectativas dos pais no desenvolvimento de um narcisismo fundamental no bebê: o bebê, ao nascer, não possui um sentimento de existência correlato ao seu corpo; dessa forma, o investimento narcísico dos pais em seus filhos é fundamental na constituição de uma imagem de base, uma imagem que representa um corpo. Nesse sentido, Dolto fala da importância da nomeação, pois na medida em que um nome designa uma unidade corporal, o bebê começa a se reconhecer nos fonemas dessa palavra e, assim, inicia-se o processo da tentativa de domínio das pulsões parciais. A autora define narcisismo como:

(...) a mesmice do ser, conhecida e reconhecida, indo-devindo para cada um no espírito de seu sexo. É desta mesmice, intensa ou tenuamente perene, que vem a noção de existência. O sentimento de existir de um ser humano, que sustenta seu corpo em seu narcisismo, sentimento que é evidente, provém desta convicção sem dúvida ilusória, de continuidade. (p. 38)

Haveria, portanto, uma relação intrínseca entre a constituição da subjetividade do bebê e de sua imagem corporal com os desejos inconscientes dos pais, pois durante seus primeiros meses de vida estaria bastante sujeito às emoções que suscita em seus cuidadores. 


\section{Envelope olfativo}

Didier Anzieu (1989) apoia-se na narrativa clínica de um paciente para desenvolver o interessante conceito de envelope olfativo. Apesar do caso não relacionar-se diretamente com o de Sandra, tal conceito contribui na articulação entre o mau cheiro e o narcisismo.

O paciente descrito é denominado Gethsêmani. Anzieu explica que realizou esta escolha por sua significação em aramaico (jardim das oliveiras), em referência direta a uma passagem da Bíblia: nos jardins das oliveiras, Jesus suou sangue na noite anterior à sua prisão pelos romanos.

$\mathrm{O}$ autor relata que nos três primeiros anos de atendimento o paciente se restringia a demonstrar sentimentos de agressividade em relação a diferentes interlocutores, como, por exemplo, seu irmão mais novo, uma madrinha e uma professora. Contudo, os afetos transferenciais apresentavam-se do avesso, posto que Gethsêmani “(...) se mostrava submisso, cheio de boa vontade, solicitando com consideração minhas interpretações e as aprovando de imediato e sem perder tempo em reflexão" (p. 206).

Anzieu, à época do atendimento, localizava uma transferência positiva, embora não constatasse a instalação de um mecanismo próprio da neurose de transferência. Curiosamente, apesar de não aparecer nas falas do paciente, um fator sempre se sobressaía nas sessões: um forte odor emitido pelo paciente. Com o passar do tempo, esse odor, misturado ao cheiro de uma colônia que utilizava (provavelmente para disfarçar o fedor), inebriava o analista e o fazia refletir sobre o lugar que esse cheiro poderia ocupar na dinâmica pulsional de Gethsêmani.

Em determinado momento, o psicanalista realizou a seguinte interpretação: "Para não sofrer desta agressividade, você a transpira através de sua pele" (Anzieu, 1989, p. 209). Por essa intervenção, o paciente acessou lembranças infantis, conteúdos relacionados à sexualidade infantil e realizou um movimento transferencial. Após esse momento, de modo geral, Gethsêmani passou a se angustiar mais e a suar menos, pois quando suava não conseguia pensar. Nesse quadro, o envelope olfativo emocional não diferencia pele das zonas erógenas: há uma totalização indiferenciada:

Face às pulsões agressivas, o Eu de Gethsêmani permanecia tão estreitamente fundido à sua pele que ele funcionava como puro Eu/corpo, sem intervenção do sistema percepção/consciência. Separando seu Eu de sua Pele, o trabalho psicanalítico permitiu a Gethsêmani apoiar sobre a pele a função de contentor psíquico, condição de funcionamento do sistema percepção/consciência. (p. 214) 


\section{ARTIGOS}

A partir desse movimento o paciente de Anzieu pôde, gradativamente, superar a dicotomia entre os afetos agressivos que vivia fora da análise e a transferência positiva submissa que vivia com o analista, bem como conseguiu inserir seus conteúdos agressivos e angustiantes na sessão. Assim, o envelope olfativo teve a função de impedir o pensamento acerca das pulsões agressivas, na medida em que os afetos "escorriam através do suor".

A noção de envelope olfativo corresponde a uma das derivações do conceito central Eu Pele: "Por eu-pele designo uma representação de que se serve o Eu da criança durante fases precoces de seu desenvolvimento para se representar a si mesma como Eu que contém os conteúdos psíquicos, a partir de sua experiência da superfície do corpo" (Anzieu, 1989, p. 44).

Esse conceito refere-se ao momento narcísico inicial da vida em que o ego começa a se diferenciar do eu corporal. Logo, o Eu Pele proporciona a integração corporal e, assim, cria a possibilidade de pensamento.

Quando Anzieu se refere à capacidade do envelope olfativo como mecanismo de defesa que separa o afeto da representação e, por consequência, impede o pensamento, duas questões emergem: O que Sandra deixa de pensar quando sente o mau cheiro? Que pulsão está evitando?

No caso de Sandra o mau cheiro aparece de duas maneiras: 1) ora como um pensamento, uma preocupação constante em relação aos outros sentirem o cheiro; e 2) ora de forma mais abrupta, um cheiro que a invade e a angustia. Esta última surge, geralmente, nos momentos em que a paciente vivencia rupturas amorosas. Dessa forma, o fedor aparece como uma ação que materializaria a angústia advinda dessa perda amorosa e, ao mesmo tempo, aparenta proporcionar um contorno corporal no exato momento em que Sandra vive uma angústia fragmentadora. É aqui que o mau cheiro parece agir conforme a descrição do Eu Pele: "A instauração do Eu-pele responde à necessidade de um envelope narcísico e assegura ao aparelho psíquico a certeza e a constância de um bem-estar de base" (p. 44).

Nesse passo, o mau cheiro parece agir de forma primitiva no psiquismo de Sandra, tanto protegendo-a de angústias eróticas avassaladoras, como produzindo uma unidade egoica em momentos de crise, pois proporcionaria uma figura diferente do outro.

\section{A morte e o sintoma}

André Green (1988) afirma que, apesar das inovações da última teoria das pulsões de Freud, principalmente no que diz respeito à pulsão de 
destruição, o conceito de narcisismo permanece ligado somente a Eros, não havendo a sua atualização pelas contribuições teóricas trazidas pelo conceito da pulsão de morte.

O autor teoriza sobre o conceito de narcisismo de morte na tentativa de incorporar a noção de narcisismo às novas dinâmicas pulsionais trazidas pela pulsão de destruição: a pulsão de morte traz consigo o princípio do nirvana, que tem, como última meta, a supressão das excitações. Logo, o narcisismo de morte seria a tendência à abolição das tensões, até ser atingido o nível zero de tensão pulsional: "Nesta perspectiva, o narcisismo primário é Desejo do Um, aspiração a uma totalidade autossuficiente e imortal onde o autoengendramento é a condição, morte e negação da morte ao mesmo tempo" (Green, 1988, p. 142).

Para Freud (1914/1996e), tanto o sono como a doença seriam momentos em que a libido se voltaria, majoritariamente, para o ego, havendo desinvestimento dos objetos. Durante a análise de Sandra, percebíamos, em diversos momentos, um movimento de recolhimento narcísico: a paciente dizia que seu único desejo era trabalhar e voltar para casa, para ficar sozinha e tranquila. Para o clínico, foi interessante perceber que esses recolhimentos não expressavam um puro movimento de morte: havia um retorno narcísico a um estado que a mantinha protegida das ameaças exteriores.

Para discorrer sobre a angústia do Um, Green (1988) recorre ao conceito de narcisismo em Freud: "Se admitirmos, como Freud já indicava, que no narcisismo o Eu procura ser amado como seu próprio ideal, é preciso considerar que a natureza do amor que o Eu dedica a si constitui um sistema tão fechado quanto possível" (p. 176). Nessas bases, em toda forma de amor haveria resquícios dessa propriedade narcísica de se manter uno. Assim, a angústia do Um se revela na possibilidade da fragmentação do Eu. Sandra, como visto, almeja muito encontrar uma pessoa para amar e que a ame. No entanto, suas experiências passadas de relacionamentos amorosos parecem ter provocado uma marca de ameaça de desfalecimento de Eu.

O mau cheiro que surge nesses momentos de crise, pensados sob a luz do narcisismo de morte, corresponde ao movimento ambivalente pulsional de morte e da negação da morte. Ela sente que está enlouquecendo com a percepção do mau cheiro, mas, ao mesmo tempo, é esse cheiro que a mantém sã.

\section{O sintoma como base da sustentação psíquica}

Freud no texto "Inibição, sintoma e angústia" (1925/1996f), descreve o complexo mecanismo das formações dos sintomas e sua relação com a 


\section{ARTIGOS}

angústia, esta seria fruto de um desamparo mental inerente à criança. Nesse sentido, o nascimento em si seria a primeira experiência de angústia que imprimiria, no inconsciente, a marca desse momento da quebra de uma situação de totalidade. A partir dessa experiência, a angústia passaria a ser um sinal que anteciparia o medo de perder o amor da mãe e, em última instância, o medo narcísico de não ter suas necessidades atendidas que se traduziria na angústia de castração.

Além do medo da perda de amor do outro, Freud (1925/1996f) também caracteriza a angústia como um afeto que protege o ego de vivenciar uma situação traumática, isto é, quando o aparelho psíquico não possui elementos elaborativos e defensivos para dar conta de uma irrupção pulsional, tanto externa quanto intrapsíquica. Em um primeiro momento, essa invasão obriga o ego a lançar mão de defesas muito primitivas; entretanto, após o trauma, o ego passaria a ter a possibilidade de, no futuro, proteger-se através do acionamento de um afeto (angústia) que lembraria o ego da situação inicial traumática. Ou seja, prepararia o ego para uma ação adequada de enfrentamento. Eis que a angústia seria uma repetição do trauma, mas de forma menos acentuada.

Freud distingue a angústia automática, que surge pela irrupção traumática, da angústia sinal, que é um estado afetivo que avisaria o ego de um perigo. Na primeira, a angústia estaria no id e seria responsável pela criação dos sintomas; na segunda, estaria alocada no ego e teria a função de acionar o recalque para, depois, constituir-se, ou não, como sintoma.

Uma vez que a situação de perigo fosse assinalada por uma angústia, restaria ao ego a tentativa de eliminar esse afeto, que ocorre através de diferentes mecanismos de defesa tais como a conversão, as representações substitutivas, as ações compulsivas, as alucinações, as projeções etc. Os sintomas seriam criados com o objetivo de remover o ego da situação de perigo, de tal modo que, se por alguma razão fosse eliminada a possibilidade de produzir um sintoma, o perigo se concretizaria, e, assim, o ego ficaria à mercê de um excesso pulsional.

Pensada como sintoma, a preocupação com o mau cheiro parece cumprir bem sua função principal: afastar a angústia de castração do âmbito egoico. Sandra passa seu cotidiano limpando casas (eliminando o mau cheiro), mas seu trabalho só aparece como fonte de angústia nos períodos em que passa a conviver, de perto, com os donos das casas. Assim, a paciente se programava para estar no trabalho nos momentos em que os moradores estivessem fora. Nem todas as pessoas provocam mal-estar, pois narrava ter amizade com alguns dos patrões. Entretanto, durante o processo analítico, por mais de uma 
vez o analista testemunhou Sandra optar por deixar de trabalhar em uma casa por achar que estavam fazendo fofocas sobre ela.

O trabalho ocupa suas energias e seus pensamentos, quase por completo. Sandra trabalha todos os dias da semana e, quando chega em casa, sempre bastante cansada, dedica-se a poucas atividades em seus momentos livres como jogar quebra-cabeças, mexer no computador e fumar narguilé. Nessa configuração de vida, Sandra encontra algum equilíbrio que a permite seguir em frente.

Acerca do equilíbrio psíquico proporcionado pelo sintoma, Fédida (1998) declara: "Será, então, possível colocar a ideia de que para cada paciente em análise, o sintoma desempenha o papel de um aparelho psíquico inédito que realiza, às vezes, sua própria ficção pelo uso que faz de uma função de um órgão" (p. 119-120).

Ainda que a manifestação do mau cheiro proporcione certo equilíbrio psíquico, inevitavelmente situações do cotidiano de Sandra comprometiam esse estado. No fundo, ela parece não se satisfazer com essa solução de compromisso, pois não se contenta em ficar só. Mesmo dizendo "não ver problema em ficar para tia e que até achava bom ficar sozinha” (sic), diversas 432 situações apontavam para a direção oposta: durante seus trajetos diários, Sandra encontra muitas pessoas e demonstra estar sempre atenta à possibilidade de encontrar um par amoroso. Sandra estava à procura, mas também se assustava muito com a possibilidade de concretizar seu desejo, pois poderia assim vivenciar novamente a angústia de perder um objeto de amor. Logo, entendemos que o mau cheiro seria o sinal de que um perigo estaria próximo. Tal perigo seria justamente o da perda do objeto de amor.

$\mathrm{O}$ mau cheiro então funcionaria como elemento que bloqueia o processo associativo da paciente. Quando vivencia o fedor, há um corte na relação direta com a situação angustiante e Sandra se volta intensamente para uma posição narcísica primitiva, de tal modo que todos os seus pensamentos e ações direcionam-se para o objetivo único de eliminar o mau cheiro. Com essa dinâmica, a angústia de castração permanece protegida, intocada: nesse momento, ela não produz um saber sobre o outro. Assim, por mais que a vivência alucinatória portasse uma carga enorme de angústia, o mau cheiro tinha a importante função de reinvesti-la narcisicamente, permitindo que encarnasse, uma vez mais, seu próprio corpo sexual. 


\section{ARTIGOS}

\section{Referências}

Abud, C. C. (2006). Dores e odores, distúrbios e destinos do olfato. Dissertação de Mestrado, Programa de Estudos Pós-graduandos em Psicologia Clínica, Pontifícia Universidade Católica de São Paulo - PUC-SP, São Paulo, SP.

Alonso, S. (2012). O tempo na escuta do analista. In F. C. Ferraz, Flávio; L. C. Fuks;

S. L. Alonso (Orgs.), Psicanálise em trabalho (p. 192). São Paulo: Escuta.

Anzieu, D. (1989). Eu pele. Trad. Zakie Yazigi Rizkallah e Rosali Mahsuz. Rev. téc. Latife Yazigi. São Paulo: Casa do Psicólogo.

Dolto, F. (1992). A imagem inconsciente do corpo. Trad. Noemi Moritz Kon e Marise Levy. São Paulo: Perspectiva.

Fédida, P. (1998, setembro). De uma psicopatologia geral a uma psicopatologia fundamental. Nota sobre a noção de paradigma. Revista Latinoamericana de Psicopatologia Fundamental, 1(3), 107- 121.

Freud, S. (1996a). Casos clínicos: Miss Lucy R. Estudos sobre a histeria. In Edição Standard Brasileira das Obras Psicológicas Completas de Sigmund Freud (V. II). Rio de Janeiro: Imago. (Trabalho original publicado em 1893-1895).

Freud, S. (1996b). Carta 55. In Edição Standard Brasileira das Obras Psicológicas Completas de Sigmund Freud (V. I). Rio de Janeiro: Imago. (Trabalho original publicado em 1897).

Freud, S. (1996c). Carta 75. In Edição Standard Brasileira das Obras Psicológicas Completas de Sigmund Freud (V. I). Rio de Janeiro: Imago. (Trabalho original publicado em 1897).

Freud, S. (1996d). Três ensaios sobre a sexualidade. In Edição Standard Brasileira das Obras Psicológicas Completas de Sigmund Freud (V. VII). Rio de Janeiro: Imago. (Trabalho original publicado em 1905).

Freud, S. (1996e). Sobre o narcisismo: uma introdução. In Edição Standard Brasileira das Obras Psicológicas Completas de Sigmund Freud (V. XIV). Rio de Janeiro: Imago. (Trabalho original publicado em 1914).

Freud, S. (1996f). Inibição, sintoma e ansiedade. In Edição Standard Brasileira das Obras Psicológicas Completas de Sigmund Freud (V. XX). Rio de Janeiro: Imago. (Trabalho original publicado em 1925-1926).

Freud, S. (1996g). Mal-estar na civilização. In Edição Standard Brasileira das Obras Psicológicas Completas de Sigmund Freud (V. XXI). Rio de Janeiro: Imago. (Trabalho original publicado em 1930).

Green, A. (1988). Narcisismo de vida, narcisismo de morte. Trad. Claudia Berliner. São Paulo: Escuta.

McDougall, J. (1997). As múltiplas faces de eros. São Paulo: Martins Fontes. 
Roudinesco, E; Plon, M. (1998). Dicionário de psicanálise. Trad. Vera Ribeiro e Lucy Magalhães. Sup. ed. bras. Marco Antonio Coutinho Jorge. Rio de Janeiro: Zahar.

\section{Resumos}

(Stench as a survival strategy)

The present paper is based on a clinical situation in which the patient seeks an analysis because all her love relationships failed causing intense suffering. Along the treatment she says that she knows why her relationships come to an end: She stinks. We formulate the clinical hypothesis that stench is inserted into the patient's psychic economy as a defense mechanism and, taking the concept of narcissism as a guide, we discuss the role of the olfactory hallucination as a psychic support for the patient.

Key words: Olfactory hallucination, narcissism, defense mechanism, psychoanalysis

(La puanteur comme une stratégie de survie)

Ce travail est basé sur le récit d'une situation clinique dans lequel le patient cherche l'analyse a cause des echècs dans toutes ses relations amoureuses lui causant des souffrances intenses. Au cours des sessions, elle dit connaitre la raison de cette condition: Elle pue. Nous formulons l'hypothèse clinique que l'odeur est insérée dans l'économie psychique du patient comme un mécanisme de défense et, en prenant le concept de narcissisme comme un guide, nous avons discuté du rôle de l'hallucination olfactive dans le soutien psychologique du patient.

Mots clés: Olfactive hallucination, narcissisme, mécanisme de défense, psychanalyse

(El hedor como estrategia de supervivencia)

El presente trabajo tiene como base la narrativa de un atendimiento clínico en lo qual la paciente busca a un análisis porque todos sus relacionamientos amorosos fallaban, generandole un gran sofrimiento. Al largo de los atendimientos ella dice saber la razón destos fracasos: ella huele mal. Hemos formulado la hipótesis clínica de que el holor malo está insertado en la economía psíquica de la paciente como un mecanismo de defensa, y tomando el concepto de narcisismo como rector, discutimos el rol de la alucinación olfativa en el sostén psíquico de la paciente.

Palabras clave: Alucinación olfativa, narcisismo, mecanismo de defensa, psicoanálisis

(Der Gestank als Überlebensstrategie)

Die vorliegende Arbeit hat als Grundlage den Bericht ueber eine klinischen Behandlung in der eine Patientie eine Analyse sucht weil alle ihre Liebesbeziehungen zerbrachen was ihr intensives Leid zufuegte. Im Zuge der Behandlung sagte sie 
sie wisse die Ursache dieser Fehlschlaege: sie stinkt.. Wir stellten die klinische Hypothese auf dass sich der schlechte Geruch in der "psychischen Oekonomie" der Patientin als Mechanismus der Verteidigung eingliedert und indem wir das Konzept des Narzismus als Ausrichtung nahmen, diskutierten wir die Rolle der Geruchshalluzination in der psychischen Haltung der Patientin.

Schlüesselwörter: Geruchshalluzination, Narzissmus, Verteidigungsmechanismus,

Psychoanalyse

\section{（作为生存战略的身体臭味）}

本论文根据临床就诊的一个病人的自我描述分析整理而成。这个病人的精 神障碍使得她所有的恋爱都以失败告终, 而多次失恋使她遭受了巨大的精神痛 苦。在求诊过程中, 该女病人说她知道为何恋爱失败: 因为她身体发出臭味。 我们根据病人的自述, 临床假定臭味是病人精神病兆中的一种自卫措施。因此 利用自恋症的概念, 我们讨论了病人的嗅觉幻觉方面的精神心理问题。

关键词：嗅觉幻觉, 自恋症, 自卫措施, 心理分析

Citação/Citation: Bonomi, T. M. A.; Berlinck, M. T. (2016, setembro). O mau cheiro como estratégia de sobrevivência. Revista Latinoamericana de Psicopatologia Fundamental, 19(3), 420-436.

Editores do artigo/Editors: Prof. Dr. Manoel Tosta Berlinck e Profa. Dra. Sonia Leite

Recebido/Received: 12.4.2016 / 4.12.2015 Aceito/Accepted: 19.6.2016 / 6.19.2016

Copyright: (C) 2009 Associação Universitária de Pesquisa em Psicopatologia Fundamental/ University Association for Research in Fundamental Psychopathology. Este é um artigo de livre acesso, que permite uso irrestrito, distribuição e reprodução em qualquer meio, desde que o autor e a fonte sejam citados / This is an open-access article, which permits unrestricted use, distribution, and reproduction in any medium, provided the original authors and sources are credited. 


\section{ARTIGOS}

Financiamento/Funding: Os autores declaram não terem sido financiados ou apoiados / The authors have no support or funding to report.

Conflito de interesses/Conflict of interest: Os autores declaram que não há conflito de interesses / The authors have no conflict of interest to declare.

\section{Tomás Moraes Abreu Bonomi}

Psicanalista; Psicólogo; Acompanhante terapêutico; Mestre em Psicologia Clínica pela Pontifícia Universidade Católica de São Paulo - PUC-SP (São Paulo, SP, Br.)

Rua dr. Alceu de Campos Rodrigues, 301/21

04507-000 São Paulo, SP, Br

e-mail: bonomitomas@gmail.com

\section{Manoel Tosta Berlinck (1936-2016)}

Sociólogo; Psicanalista; Ph.D. pela Universidade de Cornell, Ithaca, N.Y., USA; Professor aposentado da Universidade Estadual de Campinas - Unicamp (Campinas, SP, Br); Professor do Programa de Estudos Pós-Graduados em Psicologia Clínica da Pontifícia Universidade Católica de São Paulo - PUC-SP (São Paulo, SP, Br), onde dirigiu o Laboratório de Psicopatologia Fundamental; presidente (2002-2014) da Associação Universitária de Pesquisa em Psicopatologia Fundamental, editor de Pulsional Revista de Psicanálise e da Revista Latinoamericana de Psicopatologia Fundamental; Membro da World Association of Medical Editors - WAME (Associação Mundial de Editores de Medicina); Ex-diretor da Livraria Pulsional e da Editora Escuta, autor de diversos livros e numerosos artigos.

This is an open-access article, which permits unrestricted use, distribution,

\section{(cc) BY-NC} and reproduction in any medium for non-commercial purposes provided the original authors and sources are credited. 